\title{
Therapeutic Efficacy of Pain-Scrambler for Chronic Pain: A Systematic Review
}

\author{
Dong Geun Lee, Dong Hwa Heo ${ }^{凶}$, Choon Keun Park \\ Department of Neurosurgery, Spine Center, The Leon Wiltse Memorial Hospital, Suwon, Korea
}

\begin{abstract}
Objective: Pain scrambler therapy is effective for treating chronic pain. The aim of this study was to evaluate and review the effectiveness of scrambler therapy for treating refractory chronic pain. Methods: Three electronic databases (PubMed, Cochrane Database, and EMBASE.) and reference lists from relevant studies were searched in September 2015. The methodological quality of each study was assessed using the Quality Index tool. The effectiveness of the studies was measured by calculating effect sizes (Cohen's d) from means and standard deviations. Results: Eight studies including three randomized controlled trials met our inclusion criteria and were reviewed. Quality assessment scores ranged from 37 to 63\% (mean 50.3\%). External and internal validity across studies was mostly poor. However, pain scrambler therapy for chronic neuropathy appeared to be effective in higher quality studies. Conclusion: Pain scrambler therapy may be more effective for treating chronic neuropathy pain than other chronic pain; however, further research is needed to support its use to treat chronic pain considering the limited evidence.
\end{abstract}

Key Words: Pain scrambler; Neuropathy; Radiculopathy; Chronic pain.

هCorresponding author: Dong Hwa Heo, Department of Neurosurgery, The Leon Wiltse Memorial Hospital, 437 Gyeongsu-daero, Paldal-gu, Suwon 16480, Korea. Tel: 82-31-240-6283, Fax: 82-31-240-6282, E-mail: spinesurgery@naver.com

\section{INTRODUCTION}

Pain-scrambler therapy is a novel non-invasive neuromodulation technique that works by electro-cutaneous stimulation through A-delta and C-fibers. Pain-scrambler therapy is different from transcutaneous electrical nerve stimulation (TENS), which stimulates large sensory fibers and blocks pain receptors. The scrambler creates synthetic action potentials similar to endogenous action potential waveforms, which are dynamically assembled and processed by an innovative algorithm to create strings of "non-pain" information". Although randomized controlled studies for this therapy are not well established, it has been shown to be effective for relieving refractory chronic pain in some clinical trials ${ }^{4,910)}$ Pain-scrambler therapy has been used to treat cancer pain and chemotherapy-induced peripheral neuropathy $(\mathrm{CIPN})^{5,13)}$, post-herpetic neuralgia ${ }^{8)}$, neuropathic pain $^{10,14)}$ and chronic back pain ${ }^{7}$.

Acute and chronic neuropathic pain therapy, including intractable cancer pain, post-surgical pain, post-herpetic neuralgia, myofacial pain syndrome, low back pain, post-traumatic acute pain, complex regional pain syndrome, phantom pain symptoms, CIPN, Lasek/Lasik operative pain, and diabetic neuropathy are indications for pain-scrambler therapy. In particular, many studies have reported using pain-scrambler therapy for neuropathic pain ${ }^{4,10,14)}$, and the results have been quite satisfactory. Pain-scrambler therapy has also been applied to several different types of refractory chronic pain ${ }^{4}$.

The aim of this study was to evaluate and review the effectiveness of scrambler therapy for treating refractory chronic pain, including cancer pain, CIPN, post-herpetic neuralgia, and neuropathic pain.

\section{MATERIALS AND METHODS}

\section{Mechanism of the therapeutic effect}

The scrambler delivers "non pain" information to the area in pain by simulating five external artificial neurons (Fig. 1). The therapeutic principal is to replace the "pain" with "non-pain" signals. It is expected that the patient will experience an immediate reduction in pain if the electrodes are placed appropriately. Action potentials that resemble normal nerve impulses are digitally synthesized, assembled into packets of information strings, and delivered using standard silver gel electrodes similar to electrocardiogram electrodes. Each new packet is created with an algorithm that considers previous output and dynamically modifies four main variables, including 1) the type of action poten- 


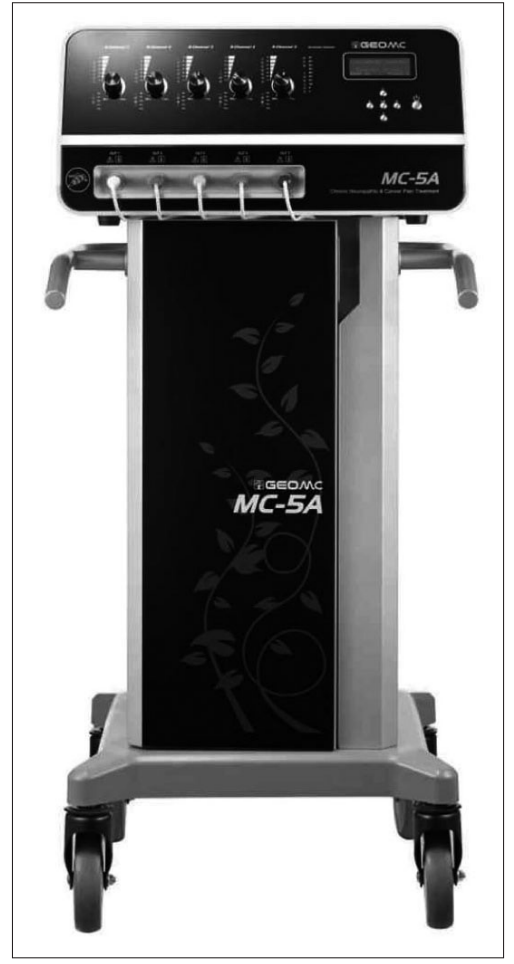

Fig. 1. The pain scrambler system.

tial to use (16 different possible combinations), 2) packet-associated frequency $(43-52 \mathrm{~Hz}), 3)$ packet time duration $(0.7-10$ sec), and 4) the amplitude of modulation. The system quickly tries different combinations until pain relief is achieved. The impulses are transmitted by surface electrodes placed on the skin in the areas of pain above and below the dermatome. The electrical charge used in scrambler therapy is low, and the U.S. Food and Drug Administration has approved it as safe. Amperage (A) is $3.50-5.50 \mathrm{~mA}$ at the highest setting of " $70^{\prime \prime}\left(10^{-70}\right.$, and maximum current density is $0.0002009 \mathrm{~W} / \mathrm{cm}^{2} .{ }^{10)} \mathrm{In}$ particular, the scrambler device generates nonlinear waveforms, as opposed to the linear waveforms of TENS. In addition, the waveforms are wide and, therefore, stimulate the $\mathrm{C}$-fibers as well as A-beta fibers and are dynamically sequenced so the nerve fibers cannot adapt ${ }^{16)}$.

\section{Technique and standard treatment}

Each patient undergoing scrambler therapy was given a 45min daily treatment for 10 consecutive days, Monday-Friday. The stimulus was increased to the maximum intensity individually bearable by the patient that did not cause any additional pain or discomfort. The principal investigator chose the best treatment areas during the first visit, which were replicated daily. The scrambler therapy group maintained their starting drug treatment with no changes. The electrodes were never applied directly on the painful area but in the dermatomes above and below the pain-affected area (Fig. 2). Once the electrodes were positioned, the operator slowly raised the stimulation level until pain relief was obtained; if no relief was obtained, the operator added or moved the channels to increase coverage.

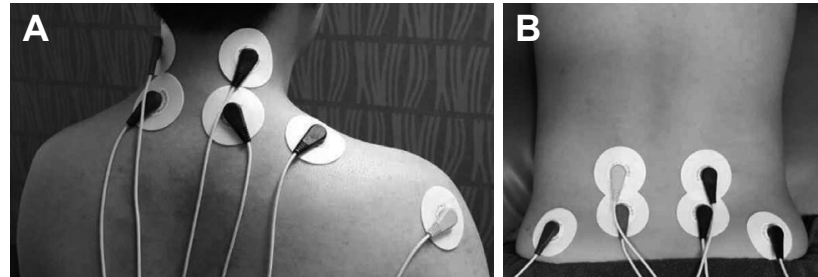

Fig. 2. Clinical application of pain scrambler therapy. Electrode placement for neck pain and shoulder radiating pain $(A)$ and back pain with buttock radiating pain $(B)$.

There were five channels or paired sets of electrodes. If pain was not relieved, the electrode placement or stimulus was changed.

\section{Search strategy to identify studies}

A systematic computerized Medline literature search was performed using PubMed, the Cochrane Database of Systematic Reviews, and EMBASE. The electronic databases were searched for articles published from January 2000 to October 2015. The searches were performed with the Medical Subject Headings (MeSH) used by the Catholic College Library of Medicine. Specifically, the MeSH terms "scrambler therapy" and "pain scrambler" were used to search PubMed, and the clinical queries filter was used to delineate only English language studies in adult patients, and with an available abstract.

\section{Data extraction and analysis}

A predefined data extraction form was used during the extraction process. Relevant data [means, mean differences, standard deviations (SDs), and $p$-values] were extracted from studies by two investigators (DGL and DHH), with specific attention to the following variables : study design, number of patients, mean age, sex, disease and pain classification, scrambler protocol used, and change in the visual analog scale score. Data pertaining to each study was assigned a numerical value to ensure that the two investigators (DGL and DHH) were blinded to the author and publication details during the quality assessment. A third assessor (CKP) made the final decision on the quality assessment score when a disagreement occurred during the quality assessment process. The effect size (Cohen's d) was calculated from means and SDs for studies that provided sufficient statistical data. Effect sizes were categorized as follows : negligible effect $(\geq-0.15$ and $<0.15)$; small effect $(\geq 0.15$ and $<0.40)$; medium effect $(\geq 0.40$ and $<0.75)$; large effect $(\geq 0.75$ and $<1.10)$; very large effect $(\geq 1.10$ and $<1.45)$, and huge effect $(\geq 1.45)^{177}$.

\section{Assessment of methodological quality}

The methodological quality of each study was assessed using the Quality Index tool developed by Downs and Black ${ }^{6}$. This tool has high internal consistency (KR-20 $=0.89$ ), good test-retest reliability $(\mathrm{r}=0.88)$, and good inter-rater reliability $(\mathrm{r}=0.75)$. The Quality Index tool consists of 27 items, and allows for assessment of internal and external validity, reporting, and power. We chose to present the quality assessment results as percentage scores, which is typical of previous studies using the Quality 
Table 1. Quality assessment scores from the Quality index tool

\begin{tabular}{|c|c|c|c|c|c|c|c|c|}
\hline Quality index items & $\begin{array}{l}\text { Starkweather } \\
\text { et al. }{ }^{16)}\end{array}$ & $\begin{array}{l}\text { Pachman } \\
\text { et al. }\end{array}$ & $\begin{array}{l}\text { Moon } \\
\text { et al. }{ }^{11)}\end{array}$ & $\begin{array}{l}\text { Coyne } \\
\text { et al. }\end{array}$ & $\begin{array}{l}\text { Smith } \\
\text { et al. }\end{array}$ & $\begin{array}{l}\text { Marineo } \\
\text { et al. }^{10)}\end{array}$ & $\begin{array}{l}\text { Sabato } \\
\text { et al. }{ }^{14)}\end{array}$ & Marineo $^{9)}$ \\
\hline \multicolumn{9}{|l|}{ Reporting } \\
\hline 1. Study hypotheses/aim/objective & 1 & 1 & 1 & 1 & 1 & 1 & 1 & 1 \\
\hline 2. Main outcomes & 1 & 1 & 1 & 1 & 0 & 1 & 1 & 1 \\
\hline 3. Participant characteristics & 0 & 0 & 0 & 1 & 1 & 1 & 1 & 1 \\
\hline 4. Interventions of interest & 1 & 1 & 1 & 0 & 1 & 1 & 0 & 1 \\
\hline 5. Distribution of principal confounders & 0 & 0 & 0 & 0 & 0 & 1 & 1 & 0 \\
\hline 6. Main findings & 1 & 1 & 1 & 0 & 0 & 1 & 1 & 1 \\
\hline 7. Estimates of random variability & 1 & 0 & 0 & 0 & 0 & 1 & 0 & 1 \\
\hline 8. Adverse events described & 1 & 1 & 1 & 1 & 1 & 1 & 1 & 0 \\
\hline 9. Participants lost to follow up described & 1 & 1 & 1 & 1 & 1 & 1 & 0 & 1 \\
\hline 10. Actual probability values reported & 1 & 0 & 1 & 0 & 0 & 0 & 0 & 0 \\
\hline \multicolumn{9}{|l|}{ External validity } \\
\hline $\begin{array}{l}\text { 11. Were subjects asked to participate representative of } \\
\text { population from which they were recruited? }\end{array}$ & 0 & 0 & 0 & 0 & 0 & 0 & 0 & 0 \\
\hline $\begin{array}{l}\text { 12. Were subjects prepared to participate representative of } \\
\text { the entire population from which they were recruited? }\end{array}$ & 0 & 0 & 0 & 0 & 0 & 0 & 0 & 0 \\
\hline $\begin{array}{l}\text { 13. Were the staff, places and facilities where the patients } \\
\text { were treated, representative of the treatment patients } \\
\text { received? }\end{array}$ & 1 & 1 & 1 & 1 & 1 & 1 & 1 & 1 \\
\hline \multicolumn{9}{|l|}{ Internal validity (bias) } \\
\hline $\begin{array}{l}\text { 14. Was an attempt made to blind study subjects to the } \\
\text { intervention they have received? }\end{array}$ & 0 & 0 & 0 & 0 & 0 & 0 & 0 & 0 \\
\hline $\begin{array}{l}\text { 15. Was an attempt made to blind those measuring the } \\
\text { main outcomes of the intervention? }\end{array}$ & 1 & 0 & 0 & 0 & 0 & 0 & 0 & 0 \\
\hline $\begin{array}{l}\text { 16. If any of the results of the study were based on 'data } \\
\text { dredging' was this made clear? }\end{array}$ & 1 & 1 & 1 & 1 & 0 & 1 & 1 & 1 \\
\hline $\begin{array}{l}\text { 17. Does analysis adjust for lengths of follow up or is the } \\
\text { time period between intervention and outcome the } \\
\text { same? }\end{array}$ & 0 & 0 & 0 & 0 & 0 & 0 & 0 & 0 \\
\hline $\begin{array}{l}\text { 18. Were the statistical tests used to assess the main } \\
\text { outcomes appropriate? }\end{array}$ & 1 & 1 & 1 & 1 & 1 & 1 & 0 & 0 \\
\hline 19. Was compliance with the intervention reliable? & 1 & 1 & 1 & 0 & 1 & 1 & & 1 \\
\hline $\begin{array}{l}\text { 20. Were the main outcome measures used accurate } \\
\text { (valid and reliable)? }\end{array}$ & 1 & 0 & 1 & 1 & 1 & 0 & 0 & 0 \\
\hline Internal validity (selection bias) & & & & & & & & 1 \\
\hline $\begin{array}{l}\text { 21. Were cases and controls recruited from the same } \\
\text { population? }\end{array}$ & 0 & 0 & 0 & 0 & 0 & 0 & 0 & 1 \\
\hline $\begin{array}{l}\text { 22. Were cases and controls recruited over the same } \\
\text { period of time? }\end{array}$ & 1 & 0 & 1 & 0 & 1 & 0 & 1 & 0 \\
\hline $\begin{array}{l}\text { 23. Were study subjects randomised to intervention } \\
\text { groups? }\end{array}$ & 0 & 0 & 0 & 0 & 1 & 1 & 0 & 0 \\
\hline $\begin{array}{l}\text { 24. Was randomised intervention assignment concealed } \\
\text { from participants/researchers until recruitment } \\
\text { complete? }\end{array}$ & 0 & 0 & 0 & 0 & 0 & 0 & 0 & 0 \\
\hline $\begin{array}{l}\text { 25. Was there adequate adjustment for confounding in the } \\
\text { analysis from which the main findings were drawn? }\end{array}$ & 0 & 1 & 1 & 1 & 0 & 1 & 0 & 1 \\
\hline 26. Were losses to follow up of patients taken into account? & 1 & 1 & 1 & 1 & 1 & 1 & 1 & 1 \\
\hline \multicolumn{9}{|l|}{ Power } \\
\hline $\begin{array}{l}\text { 27. Did the study have sufficient power to detect a clinically } \\
\text { important effect? }\end{array}$ & 1 & 0 & 1 & 0 & 0 & 1 & 0 & 0 \\
\hline Total score\% & 63 & 44 & 59 & 40 & 44 & 63 & 37 & 52 \\
\hline
\end{tabular}

All questions were scored on the following scale : yes $=1$, unable to determine $=0$, no $=0$. Question 5 is an exception with scores allocated : yes $=2$, partial$\mathrm{ly}=1, \mathrm{no}=0$ 
Index tool ${ }^{2}$. Furthermore, after obtaining data from the included studies, the findings were combined using a narrative rather than a quantitative approach, due to study heterogeneity ${ }^{3)}$.

\section{RESULTS}

Sixteen articles were identified through our electronic search. A 1980s study was excluded and one that mentioned scrambler therapy as a CIPN treatment was also excluded. A letter to the editor about scrambler therapy for chronic pain was also excluded. We could not find two of the articles by our electronic search. Finally, 10 studies were reviewed.

\section{Quality of evidence}

The inter-rater reliability of the Quality Index scores was not calculated due to the small number of trials included in the review $^{3)}$. Eight clinical articles from 10 journals were reviewed for quality, except two case series reports. Table 1 indicates that moderate study quality was identified across trials (quality assessment scores of 37-63\%; mean, 50.3\%). External validity across studies was mostly poor, due to insufficient definitions of the source population and patient selection methods and poor identification of confounding factors. The studies also rated poorly on the internal validity component of the Quality Index.

\section{Trial characteristics}

Three randomised control trials were included (Table 2). Marineo et al. ${ }^{10)}$ conducted a randomized controlled study in participants with chronic neuropathic pain to evaluate pain scrambler therapy (intervention group) against guideline-based drug man-

Table 2. Summary of clinical data from included studies

\begin{tabular}{|c|c|c|c|c|c|c|c|}
\hline $\begin{array}{l}\text { First author } \\
\text { and year }\end{array}$ & $\begin{array}{l}\text { Study } \\
\text { design }\end{array}$ & $\begin{array}{l}\text { Number } \\
\text { of patients }\end{array}$ & Mean age & Female (\%) & $\begin{array}{c}\text { Pain } \\
\text { classification }\end{array}$ & $\begin{array}{c}\mathrm{F} / \mathrm{U} \\
\text { duration }\end{array}$ & Characteristics \\
\hline $\begin{array}{l}\text { Starkweather } \\
\text { et al., 2015 }\end{array}$ & $\begin{array}{l}\text { RCT, } \\
\text { double-blinded }\end{array}$ & 30 & $\begin{array}{c}\text { Scrambler } 42.5 \\
\text { Sham } \\
45.0\end{array}$ & $\begin{array}{l}\text { Scrambler } 53 \\
\text { Sham } \\
73\end{array}$ & Low back pain & 3 weeks & $\begin{array}{l}\text { VAS } \\
\text { Scrambler } \\
\text { from } 5.40 \pm 1.5 \text { to } 3.23 \pm 1.27 \\
\text { Sham } \\
\text { from } 4.98 \pm 2.1 \text { to } 5.81 \pm 1.75\end{array}$ \\
\hline $\begin{array}{l}\text { Pachman } \\
\text { et al., 2015 }\end{array}$ & Prospective & 37 & 58 & 67.5 & CIPN & 10 weeks & $\begin{array}{l}\text { Scrambler therapy may be } \\
\text { effective for the treatment } \\
\text { of CIPN }\end{array}$ \\
\hline $\begin{array}{l}\text { Moon et al, } \\
2015^{11)}\end{array}$ & Retrospective & 147 & $37.6 \pm 16.9$ & 28.6 & $\begin{array}{l}\text { Neuropathic } \\
\text { Mixed neuropathic- } \\
\text { nociceptive }\end{array}$ & 2 months & $\begin{array}{l}\text { Neuropathic }(p=0.003) \\
\text { Mixed neuropathic }(p=0.042)\end{array}$ \\
\hline $\begin{array}{l}\text { Coyne et al., } \\
2013^{5)}\end{array}$ & Retrospective & 39 & 56.5 & 58.9 & Cancer and CIPN & 3 months & $\begin{array}{l}\text { Scrambler therapy appeared } \\
\text { to relieve cancer-associated } \\
\text { chronic neuropathic pain }\end{array}$ \\
\hline $\begin{array}{l}\text { Smith et al., } \\
2013^{15)}\end{array}$ & $\mathrm{RCT}$ & 10 & $54 \pm 13$ & 40 & PHN & 3 months & $\begin{array}{l}\text { VAS } \\
\text { from } 7.64 \pm 1.5 \text { to } 0.42 \pm 0.9\end{array}$ \\
\hline $\begin{array}{l}\text { Ko et al., } \\
2013^{8)}\end{array}$ & Case report & 3 & 71.6 & 100 & $\mathrm{PHN}$ & 4 weeks & $\begin{array}{l}\text { Scrambler Therapy can be a } \\
\text { good option for the } \\
\text { treatment of patients } \\
\text { with PHN }\end{array}$ \\
\hline $\begin{array}{l}\text { Park et al., } \\
2013^{13)}\end{array}$ & Case report & 3 & 53.3 & 66.6 & Cancer pain & 2 months & $\begin{array}{l}\text { Pain scrambler is similar or } \\
\text { superior to other existing } \\
\text { treatments in effect and } \\
\text { duration }\end{array}$ \\
\hline $\begin{array}{l}\text { Marineo et al., } \\
2012^{10)}\end{array}$ & RCT & 52 & $53 \pm 16.14$ & 61.5 & $\begin{array}{l}\text { Postsurgical } \\
\text { neuropathic pain } \\
\text { PHN } \\
\text { SCS }\end{array}$ & 3 months & $\begin{array}{l}\text { Scrambler therapy appeared } \\
\text { to relieve chronic } \\
\text { neuropathic pain better } \\
\text { than guideline-based drug } \\
\text { management }\end{array}$ \\
\hline $\begin{array}{l}\text { Sabato et al., } \\
2005^{14)}\end{array}$ & Retrospective & 226 & $\mathrm{x}$ & $\mathrm{x}$ & Neuropathy & 1 week & $\begin{array}{l}\text { Pain scrambler produced a } \\
\text { statistically significant } \\
(p<0.0001) \text { pain relief in all } \\
\text { treated neuropathies }\end{array}$ \\
\hline $\begin{array}{l}\text { Marineo et al., } \\
2003^{9)}\end{array}$ & Prospective & 11 & 72.7 & 63.5 & Cancer & 2 weeks & $\begin{array}{l}\text { Scrambler therapy are } \\
\text { extremely encouraging, } \\
\text { both in terms of enhanced } \\
\text { cancer pain control after } \\
\text { each treatment session }\end{array}$ \\
\hline
\end{tabular}


agement (control group). In this article, chronic neuropathic postsurgical pain, post-herpetic neuralgia, and spinal cord stenosis appeared to relieve pain better than guideline-based drug management over the 3 month follow-up, although this study was a small, pilot, randomized trial.

Starkweather et al. ${ }^{16)}$ conducted a pain scrambler study of low back pain and investigated 30 participants during 10 sessions of pain scrambler treatment $(n=15)$ or a sham treatment $(n=15)$ using the same device at a non-therapeutic threshold. Those authors suggested that pain scrambler treatment can be effective in reducing pain intensity and interference in individuals with persistent low back pain during the 3 week follow-up by altering the mechanisms of enhanced pain sensitivity. However, of the study enrolled a small number of patients with a short followup, and provided an obscure definition of chronic low back pain.

Moon et al. ${ }^{11)}$ investigated factors associated with predicting treatment outcomes from pain scrambler therapy over 5 years in a retrospective study. The authors insisted that a neuropathic or mixed neuropathic-nociceptive pain condition was associated with a positive treatment outcome, although they did not follow the correct protocol and the study was missing details (many unknowns) about the exact pathology, medications and doses at the start and end of the study, and the type of comorbidity (i.e., coexisting psychiatric condition of which no details were given $)^{1)}$.

\section{Efficacy of pain scrambler therapy for treating chronic pain}

Three studies investigated cancer pain, three investigated neuropathic pain, two investigated CIPN, two investigated postherpetic neuralgia, and one investigated chronic back pain. The quality of the effect for neuropathy and chronic back pain was higher than that for types of quality of pain. All authors insisted that pain scrambler therapy was effective in each study, although the studies lacked evidence. Interestingly, no pain scrambler therapy study has been published after 2000. Pain scrambler therapy appeared to be effective for chronic neuropathy in the higher quality studies.

\section{DISCUSSION}

The aim of this systematic review was to investigate the effectiveness of pain scrambler therapy for treating chronic pain. We evaluated 10 studies and identified a trend suggesting that pain scrambler therapy may be effective for improving chronic pain. Furthermore, the pain scrambler may also be a safe treatment option with few complications associated with use; however; we found average study quality in the identified studies. External validity across studies was most poor, due to deficient definitions of the source population and patient selection methods, as well as poor identification of confounding factors. Therefore, it is difficult to generalize the findings to the populations from which the study participants were derived. Furthermore, it is unknown whether participants were representative of the popula- tion from which they were recruited. As such, eight studies performed poorly on the external validity questions, scoring a mean of only $33 \%$ on questions 11-13 regarding the Quality Index tool.

All studies also rated poorly on the internal validity component of the Quality Index (questions 14-26). For example, Starkweather et al. ${ }^{16)}$ conducted a randomized controlled trial (RCT) in participants with chronic back pain to evaluate pain scrambler (intervention group) against a control (sham intervention group). However, the nature of the chronic back pain was unclear in both groups. Subsequently, various back pain groups with different origins were included. In the study by Marineo et al. $^{10)}$, the authors described the control group as receiving typical guideline-based drug management but did not clearly describe the guideline-based drug management. The lack of standardization is of particular concern considering most patients were undergoing drug and physical therapy.

The internal validity of the studies may have also been threatened due to the small number of participants. Marineo et al. ${ }^{10)}$ studied the most $(\mathrm{n}=52)$ patients, whereas Smith et al. ${ }^{15}$ investigated only 10 patients. All of the studies had weak points. The duration of follow-up was very short from 1 week to 3 months. Marineo et al. ${ }^{10}$ studied pain scrambler therapy in patients with chronic neuropathy compared to guideline-based drug management; however, the follow-up was only 3 months. Starkweather et al. ${ }^{16)}$ studied pain scrambler therapy for chronic low back pain but only for 3 weeks. Further study is warranted to determine long-term outcomes after pain scrambler therapy, including functional status, analgesic use, and healthcare utilization.

The pain scrambler protocol varied between studies, resulting in heterogeneity and making it difficult to compare results. Specifically, differences in duration, frequency, and strength of the pain scrambler application were identified between studies. There is also a learning curve with this treatment, and results improve over time $\mathrm{e}^{12}$.

This systematic review identified a number of important implications for future research. First, with double-blinded RCTs are essential to evaluate the effectiveness of the pain scrambler for treating chronic pain to reduce bias. Second, outcome measures must be reliable and valid and include both specific and generic measures, as well as detailed information about the criteria used to identify the chronic pain classification, as there was substantial variability in the criteria used. Third, acknowledgement and adjustment for confounding variables should be included in future trials and analyses should be stratified based on the type of chronic pain. This will ensure that trials include sufficient information so the methods can be critiqued and allow comparisons to be made with similar investigations. Finally, the optimal pain scrambler regimen remains to be established and should be the focus of future studies.

Existing evidence supports the use of a pain scrambler regimen for treating chronic pain in light of some limitations. First, only 10 studies (three of which were RCTs) investigated the effects of pain scrambler therapy, and small participant numbers were 
included in the studies. Second, this review identified significant methodological heterogeneity between studies. For example, one of the studies included post-surgical pain, post-herpetic neuralgia, and spinal cord stenosis as chronic pain types ${ }^{10)}$. Third, the definitions used to determine changes varied between studies. Some limitations of this review include no pooling of data for meta-analysis and no statistical measure of heterogeneity was performed.

\section{CONCLUSION}

This systematic review identified 10 studies that reported on the effectiveness of pain scrambler therapy for treating chronic pain. Pain scrambler therapy appeared to be effective for chronic pain neuropathy. However, limited evidence supports its use for treating other types of chronic pain. Further research is needed to support the use of pain scrambler therapy for treating chronic pain.

\section{REFERENCES}

1. Abdi S, Smith TJ, Marineo G : Scrambler Therapy for Chronic Pain. Clin J Pain 31 : 929, 2015

2. Butterworth PA, Landorf KB, Smith SE, Menz HB : The association between body mass index and musculoskeletal foot disorders : a systematic review. Obes Rev 13 : 630-642, 2012

3. Butterworth PA, Walsh TP, Pennisi YD, Chesne AD, Schmitz C, Nancarrow SA : The effectiveness of extracorporeal shock wave therapy for the treatment of lower limb ulceration : a systematic review. J Foot Ankle Res $8: 3,2015$

4. Compagnone C, Tagliaferri F : Chronic pain treatment and scrambler therapy : a multicenter retrospective analysis. Acta Biomed 86 : 149-156, 2015

5. Coyne PJ, Wan W, Dodson P, Swainey C, Smith TJ : A trial of Scrambler therapy in the treatment of cancer pain syndromes and chronic chemotherapy-induced peripheral neuropathy. J Pain Palliat Care Pharmaco- ther $27: 359-364,2013$

6. Downs SH, Black N : The feasibility of creating a checklist for the assessment of the methodological quality both of randomised and non-randomised studies of health care interventions. J Epidemiol Community Health 52 : 377-384, 1998

7. Ghatak RK, Nandi SN, Bhakta A, Mandal GC, Bandyopadhyay M, Kumar S : Prospective study of application of biological communication (cybernatics) in management of chronic low back pain--a preliminary report. Nepal Med Coll J 13 : 257-260, 2011

8. Ko YK, Lee HY, Lee WY : Clinical experiences on the effect of scrambler therapy for patients with postherpetic neuralgia. Korean J Pain 26 : 98101,2013

9. Marineo $\mathrm{G}$ : Untreatable pain resulting from abdominal cancer : new hope from biophysics? JOP 4 : 1-10, 2003

10. Marineo G, Iorno V, Gandini C, Moschini V, Smith TJ : Scrambler therapy may relieve chronic neuropathic pain more effectively than guidelinebased drug management : results of a pilot, randomized, controlled trial. J Pain Symptom Manage 43 : 87-95, 2012

11. Moon JY, Kurihara C, Beckles JP, Williams KE, Jamison DE, Cohen SP : Predictive factors associated with success and failure for Calmare (Scrambler) therapy : a multicenter analysis. Clin J Pain 31 : 750-756, 2015

12. Pachman DR, Weisbrod BL, Seisler DK, Barton DL, Fee-Schroeder KC, Smith TJ, et al. : Pilot evaluation of Scrambler therapy for the treatment of chemotherapy-induced peripheral neuropathy. Support Care Cancer 23 : 943-951, 2015

13. Park HS, Sin WK, Kim HY, Moon JY, Park SY, Kim YC, et al. : Scrambler therapy for patients with cancer pain - case series. Korean J Pain 26 : 65 71,2013

14. Sabato AF, Marineo G, Gatti A : Scrambler therapy. Minerva Anestesiol $71: 479-482,2005$

15. Smith TJ, Marineo G : Treatment of postherpetic pain with scrambler therapy, a patient-specific neurocutaneous electrical stimulation device. Am J Hosp Palliat Care, 2013

16. Starkweather AR, Coyne P, Lyon DE, Elswick RK Jr, An K, Sturgill J : Decreased low back pain intensity and differential gene expression following Calmare $(\mathrm{R})$ : results from a double-blinded randomized sham-controlled study. Res Nurs Health $38:$ 29-38, 2015

17. Thalheimer W, Cook $\mathrm{S}$ : How to calculate effect sizes from published research articles: a simplified methodology. Available from : http://www. bwgriffin.com/gsu/courses/edur9131/content/Effect_Sizes_pdf5.pdf 